\title{
A EDUCAÇÃO AMBIENTAL COM AS COMUNIDADES TRADICIONAIS: OUTRAS TRAJETÓRIAS DE SUSTENTABILIDADES
}

\author{
ENVIRONMENTAL EDUCATION WITH TRADITIONAL COMMUNITIES: \\ OTHER SUSTAINABILITY TRAJECTORIES
}

\author{
EDUCAÇÃO AMBIENTAL: SUSTENTABILIDADES EM COMUNIDADES \\ TRADICIONAIS
}

\section{ENVIRONMENTAL EDUCATION: SUSTAINABILITIES IN TRADITIONAL COMMUNITIES}

\author{
VIEIRA, Fabio Pessoa ${ }^{1}$ \\ SOUZA, Lucas Barbosa $\mathrm{e}^{2}$
}

\begin{abstract}
Resumo
$\mathrm{O}$ artigo propõe-se evidenciar outra perspectiva de sustentabilidade. Perspectiva díspar do desenvolvimento sustentável pautado por uma racionalidade econômica. Inicialmente destacaremos a conformação do mundo moderno-colonial e como ocorrem as ressonâncias do conceito de desenvolvimento sustentável, na Educação Ambiental, para posteriormente, apoiados no pós-colonialismo buscarmos possibilidades de sustentabilidades locais. Para isto analisaremos dois documentos que apontam concepções distintas de Educação Ambiental e depois apresentaremos uma trajetória de sustentabilidade existente em uma comunidade tradicional, com histórias narradas pelas mulheres quebradeiras de coco, da Reserva Extrativista do Extremo Norte do Tocantins. O pós-colonialismo alicerça teoricamente e epistemicamente a argumentação presente no texto. $\mathrm{O}$ método da análise documental e a técnica da narrativa dão suporte à estrutura metodológica. Como resultados, compreendemos a sustentabilidade sendo produzida em um diálogo com outros saberes, mais especificamente de comunidades tradicionais, rompendo com o produzido pela sociedade moderno-colonial que ao propor uma única maneira de ser sustentável, despreza as experiências vividas e os diversos saberes.
\end{abstract}

\footnotetext{
${ }^{1}$ Licenciado e Bacharel em Geografia. Mestre em Educação (UFBA) e Doutorando em Ciências do Ambiente (UFT). Professor Assistente da Universidade Federal do Tocantins (UFT). Campus de Tocantinópolis-TO. Curso de Pedagogia. fabiopessoa@uft.edu.br

${ }^{2}$ Licenciado e Bacharel em Geografia. Mestre e Doutor em Geografia. Professor Associado da Universidade Federal do Tocantins (UFT). Campus de Porto Nacional-TO. Curso de Geografia. lbsgeo@ uft.edu.br.
} 
Palavras-Chave: reserva extrativista; mulheres quebradeiras de coco; pós-colonialismo

\begin{abstract}
The article proposes to highlight another perspective of sustainability. A disparate perspective of sustainable development based on economic rationality. Initially we will highlight the conformation of the modern-colonial world and how the resonances of the concept of sustainable development in Environmental Education occur, and later, supported by postcolonialism, we seek possibilities for local sustainability. In order to do this, we will analyze two documents that point out distinct conceptions of Environmental Education and then present a path of sustainability existing in a traditional community, with stories narrated by the coconut breakers women of the Extractive Reserve of the Far North of Tocantins. Postcolonialism theoretically and epistemically supports the argument in the text. The method of documentary analysis and the narrative technique support the methodological structure. As results, we understand sustainability being produced in a dialogue with other knowledge, more specifically of traditional communities, breaking with the one produced by the moderncolonial society that, in proposing a unique way of being sustainable, despises lived experiences and diverse knowledges.
\end{abstract}

Keywords: extractive reserve; coconut breakers women; postcolonialism

\title{
Introdução
}

O presente texto busca apresentar as ressonâncias, na Educação Ambiental, do conceito de desenvolvimento sustentável delineado no mundo moderno-colonial. O objetivo é contrapor a ideia de que o desenvolvimento sustentável é único para todos os locais. Para tanto, os saberes constituídos em comunidades tradicionais, que aqui serão representados por narrativas de quebradeiras de coco, alicerçados em uma forte ligação com a natureza em seu cotidiano, emerge como uma alternativa de sustentabildade.

Emerge também, epistemicamente, como um contraponto ao discurso do desenvolvimento e do progresso, associado à ideia de desenvolvimento sustentável, como se este fosse homogêneo nos diversos espaços tempos, desprezando as singularidades dos territórios e dos lugares. Tal homogeneização apresenta-se como uma imposição em uma relação colonial vigente no nosso mundo.

Imposição apoiada no paradigma da modernidade, e que se se refere à maneira como a humanidade relaciona-se com a natureza - tornada como mercadoria, passível de apropriação desigual por parte de diferentes grupos sociais - de maneira exploratória e pautada por uma 
racionalidade econômica. Tal forma de relacionar-se ganha ênfase com a conformação do mundo moderno-colonial e se mantém até os dias atuais, potencializada pelo discurso do desenvolvimento sustentável. Discurso este que visa uma conservação dos recursos naturais com o intuito de manter um status quo da natureza como mercadoria.

Como aporte teórico e epistêmico para o presente estudo, utilizamos o póscolonialismo. Com este, intentamos uma desconstrução paradigmática, que visa propiciar destaque ao lugar, na qual uma alternativa de sustentabilidade, constituída no cotidiano de uma comunidade tradicional, seja uma possibilidade de atualização para uma Educação Ambiental que incorpore a narrativa de povos que tiveram seus saberes historicamente subjugados.

A técnica da análise documental foi utilizada, para compreendermos trechos de dois documentos que embasam a Educação Ambiental, com foco em suas compreensões sobre a sustentabilidade. Utilizamos também, a técnica da narrativa para coletarmos as descrições verbais de três quebradeiras de coco. Não visamos utilizar a descrição como uma mera técnica de pesquisa, mas sim como uma expressão da riqueza do cotidiano existente em uma comunidade tradicional

A estrutura do artigo centra-se em três momentos: o surgimento do mundo modernocolonial e como, neste mundo, emerge o discurso do desenvolvimento sustentável; as ressonâncias do desenvolvimento sustentável na Educação Ambiental; e por fim apresentar uma alternativa de sustentabilidade, em um exercício pós-colonial, constituída com os saberes das quebradeiras de coco em uma reserva extrativista.

\section{Um mundo, um conceito e uma educação: um exercício de desconstrução}

Três eventos emergem - o mundo moderno-colonial, o conceito de desenvolvimento sustentável, e a Educação Ambiental - com suas singularidades, mas que se entrelaçam a partir de uma perspectiva colonizadora, não apenas do território, mas também em uma vertente epistêmica, na produção do conhecimento. Tais eventos auxiliam na validação de uma forma de relação do ser humano com a natureza centrada em uma racionalidade econômica. Os dois primeiros serão brevemente abordados a fim de buscarmos compreender as ressonâncias, na forma de produção de conhecimento, que estes impuseram ao último. 
Assim, nos ateremos em discorrer sobre a Educação Ambiental, com o intuito de conhecermos possibilidades de alternativas locais de sustentabilidade.

Um mundo, o moderno-colonial, que teve o seu início, conforme aponta PortoGonçalves (2013), a partir da afirmação da Europa como centro hegemônico do mundo no final do século XV. Um conceito, o desenvolvimento sustentável, que emerge como uma tentativa de garantir que os homens e mulheres possam viver em um "ambiente saudável" a partir da ideia de que os seres humanos têm a obrigação de garantir esse "ambiente saudável" às gerações futuras. Uma educação, a ambiental, que tenha como pressupostos a mera transmissão de informações, e que propõe uma "conscientização", por parte das pessoas, no sentido de se constituir novos valores e novos hábitos para que os problemas na degradação do ambiente venham a ser sanados.

A busca, neste texto, é por um exercício de desconstrução, dos três eventos apresentados, que para se efetivar intenta dar vez e voz aos saberes de povos existentes em comunidades tradicionais. Tal exercício de desconstrução visará compreender outras possibilidades do ser humano para se relacionar com a natureza, assim como compreendermos outras possibilidades de se produzir a Educação Ambiental. Possibilidades que tenham como base um envolvimento com o mundo, constituído no lugar.

O lugar, compreendido como um território de acontecimento, em que há um elo existencial entre o ser e o espaço e no qual ocorre uma multiplicidade de vivências que propiciam um envolvimento, em uma relação ética, expressada por um enraizamento, entre o ser humano e a Terra. Mais do que um conceito ou uma abstração, o lugar, é um espaço que se constitui a partir de uma vivência e significação, pertencimento e envolvimento tal qual enfatiza Relph (1979, p.17): "Não se refere a objetos e atributos das localizações, mas a tipo de experiência e envolvimento com o mundo, à necessidade de raízes e de segurança”. Lugar no qual a vida se realiza e que o cotidiano acontece, o que coaduna com o proposto por Marandola Júnior (2014, p.230) “[...] mais do que um conceito científico de conteúdo abstrato, lugar se refere à mundanidade de nosso cotidiano, e por isso ele é fundamental quando pensamos o ser-no-mundo e a existência”.

Retornamos aos eventos, para apresentar inicialmente o mundo moderno-colonial. Este tem como central, em sua conformação, a invasão do continente americano pelos europeus a partir do final do século $\mathrm{XV}$, e constitui-se em um sistema que dá início a uma 
primazia de organização de mundo à Europa. Um mundo que passa a não ser mais, em termos espaciais e territoriais, a própria Europa. Assim, Quijano e Wallesrtein (1992, citado por, MIGNOLO, 2005) denominaram o sistema mundo moderno-colonial.

O olhar que será dado a este mundo não é a de sua afirmação ou da constituição de seu imaginário, que nega o conflito que surge da diferença colonial como destaca Mignolo (2005), "mas sim um olhar que contemple dar visibilidade à colonialidade do poder" (QUIJANO 2005), como sendo uma estratégia da modernidade que contribui de maneira essencial para a autodefinição do que seja a Europa e o seu consequente impacto sobre a natureza.

Esse mundo baseou-se na expropriação de diversos povos originários do seu território, criando territorialidades que servem ao interesse restrito dos países centrais que controlam o mundo moderno-colonial, e à custa de uma forte degradação ambiental. Baseou-se, também, em um entendimento de que os territórios a serem conquistados, apoiando-se em uma vertente economicista, fossem utilizados como fonte de recursos e incorporados ao progresso e desenvolvimento a partir da relação de poder imposta pelos invasores, negando a cultura dos povos já ali existentes.

Com o objetivo de manter o status quo desenvolvimentista, surge o conceito de desenvolvimento sustentável. Proposto pela ONU e presente em um documento nominado Nosso Futuro Comum (1991), tal conceito preconiza que é: "[...] aquele que atende às necessidades do presente sem comprometer as possibilidades das gerações futuras atenderem suas próprias necessidades" (COMISSÃO MUNDIAL DO MEIO AMBIENTE E DESENVOLVIMENTO, 1991.p.09).

Uma análise sobre tal conceito pode propiciar algumas indagações: De quais necessidades esse conceito explana? Necessidades eminentemente humanas, como alimentação, moradia e condições básicas de saúde, tal como o saneamento? Necessidade de manter um padrão de consumo com vistas a um modelo de desenvolvimento impossível de ser atingido por todas as localidades do planeta? Neste artigo, não nos debruçaremos para responder tais questões, mas, sim, apresentar as ressonâncias deste conceito na Educação Ambiental, visando, em uma perspectiva pós-colonial apresentar uma alternativa de sustentabilidade constituída em uma comunidade tradicional. 


\section{A sustentabilidade na Educação Ambiental}

A Educação Ambiental, seja em seu percurso histórico, seja em sua diversidade de concepções, possui uma ampla discussão acadêmica, no Brasil, a partir da produção de diversos autores. Dentre eles, temos Reigota (1995), Loureiro (2006), Layrargues (2006), Guimarães (2004). Por este motivo, não iremos prolongar este debate. O intuito é apresentar as ressonâncias do conceito de desenvolvimento sustentável na Educação Ambiental, a partir do olhar hegemônico, e tendo como contraponto uma abordagem pós-colonial.

A priori, os referenciais, na Educação Ambiental conduzem de maneira bastante homogênea à discussão de um possível desenvolvimento sustentável que serviria a todos os territórios, de forma igualitária, a partir da premissa de que todos pudessem alcançar um satisfatório desenvolvimento social e econômico.

Essa matriz ratificada pelo pensamento moderno-colonial induz para que $o$ desenvolvimento sustentável torne-se um discurso necessário, sobretudo, aos interesses dos segmentos hegemônicos que conduziram o planeta à degradação ambiental. Induz também, para que a Educação Ambiental construída em torno de aspectos tecnicistas, como se esses fossem capazes de dar conta da problemática ambiental, tal qual delineada, encobre os reais causadores da problemática ambiental, que se constitui em sua essência a partir da separação ser humano/natureza, e da ideia de acumulação e de objetivação construída sobre a natureza. Essa construção diminui as possibilidades de pensarmos caminhos de uma real interação dentre os sujeitos que constroem a Educação Ambiental com o seu mundo-vivido e o seu lugar. Tal diminuição é consolidada à medida que confere a uma ciência desenvolvida por um viés tecnicista-colonialista, e que subjuga uma diversidade de saberes e as subjetividades, o poder de ditar as regras de formação da Educação Ambiental.

Assim, ao traçarmos um percurso de como o conceito de desenvolvimento sustentável ressoa na Educação Ambiental, direcionamos o olhar para as concepções, conservacionista e pragmática, pois compreendemos que estas reforçam a crença de que a criação de "bons" hábitos nos humanos, de maneira individualista para com a natureza e as inserções de novas tecnologias é suficiente para solucionar a degradação ambiental. Aqui, há um grave equívoco na ideia de que novas técnicas solucionarão os problemas ambientais.

A leitura que fazemos é justamente, que o uso excessivo das tecnologias - que em uma sociedade capitalista está a serviço do aumento da produtividade e, consequentemente do 
lucro, - é o responsável por um viés de dominação e de conquista da natureza. Técnicas que cada vez mais submetem os seres humanos a comportamentos previsíveis, por conta de uma racionalidade econômica que subjuga os lugares a uma lógica dominante e global. Isto inviabiliza entender que um dos maiores expoentes do paradigma da modernidade, possa nos permitir construir outra trajetória de relação com a natureza.

Desta maneira ficamos presos em uma "armadilha paradigmática", (GUIMARÃES, 2006), na Educação Ambiental, na qual há a manutenção de uma racionalidade hegemônica fragmentária, simplista e que reduz a realidade, limita a compreensão e outras possibilidades de discursos, uma vez que esta educação é constituída sob as égides do paradigma modernocolonial.

A difusão da Educação Ambiental, inclusive por intermédio de documentos oficiais, é oriunda das discussões ocorridas nas Conferências de Estocolmo em 1972, e Intergovernamental de Educação Ambiental, em Tblisi no ano de 1977 (SILVA, 2007), ou seja, quase quatro décadas depois nos parece que a discussão existente na Educação Ambiental necessita de outras trajetórias. Trajetórias que destoem, por exemplo, da Educação Ambiental conservacionista destacada e criticada por Layrargues (2006), como uma educação com foco no ambiente e não o humano, bem como em aspectos procedimentais em uma perspectiva individualista, e que aborda basicamente as ciências naturais como conteúdo. Esta educação surgiu com o intuito de criar bons comportamentos nos seres humanos, a partir de uma conscientização ambiental.

Compreendemos que há um individualismo presente na proposição de atitudes ecologicamente "corretas", o que nos afasta de um exercício autônomo e de uma unidade comum para com a natureza. Assim, os seres humanos, de maneira isolada, se responsabilizam pela resolução de um problema extremamente complexo, a degradação ambiental, por meio de propostas educativas inócuas. Individualismo, que dificulta também, a compreensão da verdadeira gênese dos problemas ambientais, que não estão vinculados à ação isolada de cada indivíduo, mas a valores hegemônicos que interessam especialmente a determinados grupos sociais.

Por conseguinte, as atenções de uma Educação Ambiental conservacionista estão centradas nas consequências - erosão dos solos, enchentes nas cidades, escassez de recursos, dentre outros. Isto inviabiliza a busca por uma compreensão das causas basilares da crise 
ambiental, em especial a separação ser humano/natureza que concede à conformação de um mundo, no qual o ser humano tem autorização para espoliar a natureza e torná-la sua serva.

Por sua vez, a Educação Ambiental pragmática, que é erigida pelo mesmo paradigma da modernidade, apresenta o foco nas ações humanas e na proposição de normas a serem seguidas. Tal concepção de Educação Ambiental busca também, por intermédio das técnicas compatibilizar desenvolvimento econômico com manejo sustentável (SILVA, 2007). Desta maneira, como na concepção conservacionista, há a tendência em acreditar que a gravidade da situação ambiental necessita de mudanças no comportamento dos cidadãos, exigindo ações práticas e imediatistas.

Por conseguinte, a ideia de normas e regras impostas como modelos prontos, no que se refere à Educação Ambiental, dificulta outras possibilidades de constituir um conhecimento que tenha como base os saberes que comunidades tradicionais historicamente produziram, mas, que foram subjugados por uma lógica colonizadora. Uma educação, que deixe de ser condicionada e fundamentada um desenvolvimentismo estritamente econômico, e torne-se incompatível com o percurso e a história de vida de quem produz saberes e cultura relacionados diretamente com o seu ambiente.

Entretanto, antes de delinearmos uma alternativa local de sustentabilidade para a Educação Ambiental buscaremos compreender as ressonâncias do discurso do desenvolvimento sustentável na Educação Ambiental, que vem sendo produzida e discutida. Para isto, utilizamos como instrumento de análise, dois documentos que embasam a Educação Ambiental.

Destacaremos aspectos, referentes à temática do desenvolvimento sustentável. Seja um desenvolvimento sustentável, pensado e produzido de cima para baixo como um território a ser colonizado, ou seja, pensado e produzido com as concepções e saberes de diversos povos tradicionais que constituem por intermédio de um modo de vida, uma Educação Ambiental autônoma e vivida.

Na perspectiva do que pode vir a ser colonizado, incluímos a colonização das "mentes" dos que propõem, constroem e praticam a Educação Ambiental ao reforçarem a ideia de que é possível um modelo de desenvolvimento econômico igual para todos. Contudo, o modelo almejado é justamente o que criticamos por ser originado do mundo modernocolonial que se assenta em uma relação de exterioridade da natureza, e de uma consequente 
objetificação da mesma. Enfim, um modelo econômico desenvolvimentista que preconiza "[...] um padrão de igualdade conforme uma visão eurocêntrica, um padrão cultural que se crê superior e por isso, passível de ser generalizado" (PORTO-GONÇALVES, 2013, p.64).

A técnica da análise documental, como apontam Sá-Silva, Almeida e Guindani (2009), foi utilizada para produzirmos ou reelaborarmos conhecimentos e criarmos novas formas de compreender os fenômenos, em um processo de interpretação e sintetização das informações.

O documento Education for Sustainable Development de McKeown (2002), traz em sua estrutura uma abordagem homogênea, sobre o desenvolvimento sustentável, e que empobrece as possibilidades de se pensar uma Educação Ambiental constituída com saberes de comunidades tradicionais. A escolha de tal documento consiste em apresentar um olhar, colonizador e hegemônico, que é produzido sobre a sustentabilidade por uma autora estadunidense. Vejamos alguns trechos, que reforçam a condição de desenvolver uma Educação Ambiental, na qual o paradigma da modernidade potencialize aspectos que priorizem:

Uma relação excludente, patriarcal e que impute aos que ao longo do espaço tempo tiveram suas histórias e seus direitos negados, tais como as mulheres, a responsabilidade pela degradação ambiental.

Os aumentos na população e o uso de recursos deverão ser repensados para não comprometer um futuro sustentável que está ligado tanto a taxa de fecundidade quanto a de consumo de recursos. Educar fêmeas reduz taxas de fertilidade e, portanto, o crescimento da população (MCKEOWN, 2002, p.10 tradução nossa).

Um documento que reforça o desenvolvimento econômico, negando as consequências causadas por esse modelo... "O paradigma da sustentabilidade rejeita a afirmação de que as baixas nos reinos ambientais e sociais são conseqüências inevitáveis de desenvolvimento econômico" (MCKEOWN, 2002, p.8 tradução nossa).

Documento que aponta aspectos que mantenham a ideia de que as nações por intermédio de acordos e tratados resolverão os problemas ambientais. "Nações devem reduzir e eliminar padrões insustentáveis de produção e consumo, e promover políticas demográficas adequadas" (MCKEOWN, 2002, p.9 tradução nossa). 
Orientados por um viés pós-colonial, rechaçamos tais ideias, pois compreendemos que as nações, pressupõem uma certa homogeneidade. No caso específico do Brasil, com a vasta sociobiodiversidade existente em seu território, e sua complexa formação social, entendemos que uma pretensa homogeneidade, seja nos aspectos culturais, seja nos aspectos físicos, nos permite entender que o discurso de nação tramado, em especial, a partir de uma exploração na relação colonizado/colonizador, nega a real heterogeneidade espacial e social existente em uma multiplicidade de lugares.

Em síntese, o que vimos no documento apresentado, foi a prevalência de um viés preservacionista e conservacionista na lógica do desenvolvimento sustentável que tem forte relação, na sua produção e na sua execução, com a ideia de que o ambiente "[...] deve ser preservado desde que seja compatibilizado com a lógica da economia mercantil, ou melhor, com a acumulação de capital" (PORTO- GONÇALVES, 2013, p.275). Em conformação com esse viés, conforme já destacamos, há uma vinculação e dependência da técnica e do cientificismo e à simples mudança de comportamento dos sujeitos que praticam a Educação Ambiental, para que de fato o sustentável seja alcançado:

Avançar na perspectiva de uma sociedade sustentável, implica, entre muitas outras coisas, tornar as indústrias mais eficientes, diminuindo o desperdício e reduzindo a produção de lixo tóxico ou não-tóxico; controlar a poluição das águas; realizar o manejo florestal; reciclar materiais. (BRASIL, 1998, p.220).

Com o intuito de contrapor a produção de um conhecimento que vê a Educação Ambintal e a sustentabilidade como mais um elemento de colonização dos lugares e dos saberes, destacaremos trechos de um documento, produzido e pensado para permitir outras trajetórias de sustentabilidade.

O Programa latino-americano e caribenho de educação ambiental no marco do desenvolvimento sustentável - é um documento elaborado a partir do IV Congresso Iberoamericano de Educação Ambiental, ocorrido em Cuba, em 2003 e originado a partir da formação do Programa Latino-americano e Caribenho de Educação Ambiental, constituído em 1992. 
A América Latina e Caribe representam uma das áreas do planeta com maior riqueza natural e social do mundo. Possui zonas de mega-diversidade tanto terrestre como marinha, grandes reservas de água e biomas de enorme valor ambiental, científico, social, cultural e econômico [...] Contrastando com isso, a implantação em toda a região de modelos de desenvolvimento baseados na exploração econômica de curto prazo e na ilusão de que o crescimento econômico pudesse solucionar os males derivados da falta de justiça social e a responsabilidade ambiental, erodiu e ameaçou a existência mesma da riqueza biológica e social em todos os países deste vasto território. Essa situação se agravou nos últimos anos com o surgimento de problemas ambientais em escala planetária, e com o surgimento de transtornos sócioambientais crônicos e crescentes como pobreza, desertificação, esgotamento de recursos hídricos, catástrofes ambientais, epidemias, extinção de culturas tradicionais (BRASIL, 2005, p.11).

O fragmento aponta que o modelo de desenvolvimento do mundo moderno-colonial põe em risco a riqueza da sociobiodiversidade em toda região, a partir de sinais preocupantes de uma grave degradação ambiental. Um processo de mudanças caracterizadas por lutas sociais que pretendem reverter esta situação e conquistar o reconhecimento e a legitimação de seus saberes é um exercício realizado por diversos povos tradiconais, o que permite a produção de sua própria pedagogia de vida e que ressoa em defesa da natureza.

A noção de Desenvolvimento Sustentável nem sempre foi bem aceita: Para muitos ela é um conceito ambíguo que se presta a muitas interpretações, algumas destas incompatíveis entre si. Podemos incluir aí as tentativas, nem sempre bem dissimuladas, de usar o conceito para maquiar projetos que se baseiam unicamente na racionalidade e em interesses econômicos de grupos ou estados poderosos. Mesmo assim, existe um consenso sobre a necessidade de se promover o conceito de sustentabilidade como orientação fundamental na construção de sociedades capazes de atender as necessidades humanas de maneira democrática e eqüitativa e preservar a longo prazo a base ambiental e a diversidade cultural dos povos. (BRASIL, 2005, p.11).

Se por um lado a ambiguidade do conceito de desenvolvimento sustentável serve ao atual modelo de sociedade, na medida em que a racionalidade econômica sobrepõe-se à racionalidade ecológica e não como muitas vezes pretende parecer o oposto, por outro lado há possibilidades de se pensar outras sustentabilidades fundadas na ética e compromisso da humanidade para com a natureza, tendo como referência o entendimento de que os seres humanos estão com a natureza e não sobre esta. 
O caminho para uma sociedade sustentável pressupõe transformações nos padrões de produção e consumo, nos valores existentes hoje nas relações entre o homem e a natureza e na forma de interagir e de comunicação entre as pessoas. Isso implica em mudar o processo de tomada de decisões sobre o desenvolvimento humano, que deve se democratizar, fortalecendo as comunidades locais assim como as pessoas diretamente afetadas pelos processos de transformação tecnológica e social. Tudo isso conduz a repensar as relações das comunidades humanas com a natureza e consigo mesmas, o que inclui todas as relações de poder: homem - mulher, adulto criança, comunidades - autoridades, brancos - outras etnias, ricos - pobres, entre outras. (BRASIL, 2005, p.12).

Pensar a sustentabilidade implicando em mudanças de princípios na relação do ser humano com a natureza é o que há de destaque no fragmento exposto. Princípios que acarretem em modificações acerca do consumismo constituído na sociedade contemporânea, na qual a justiça social seja construída a partir dos saberes e demandas de comunidades tradicionais. Isto direciona para reexaminar as relações de poder existentes na contemporaneidade, e fortemente solidificada pelo mundo moderno-colonial, o que inclui atitudes mais coletivas e humanas e menos racionalizadas a partir do patriarcalismo e colonialismo.

\begin{abstract}
No mundo ibero-americano, e especialmente na América Latina, a educação ambiental se desenvolveu de maneira desigual e diversa. Esse desenvolvimento foi marcado de um lado pela influência unificadora das orientações internacionais e as hegemonias culturais; de outro, ele se contrapôs a essas tendências, às próprias características e particularidades sócio-políticas e culturais, tanto às regionais latino-americanas como àquelas especificamente nacionais. Estas circunstâncias geraram um mosaico de experiências muito diversas, de grande riqueza conceitual e metodológica. [...] Fortalecer os aspectos conceituais e metodológicos da educação ambiental e do desenvolvimento sustentável segundo uma ótica regional. Estabelecimento de seminário permanente de discussão epistemológica, axiológica e de construção de conceitos em educação ambiental e sustentabilidade. (BRASIL, 2005, p.13).
\end{abstract}

A diversidade de saberes e conhecimentos existentes na América Latina, com os mais diversos povos permite uma pluralidade de trajetórias para constituir a Educação Ambiental. Isto, mesmo com a perspectiva colonizadora que subjuga os conhecimentos dos povos da região, e despreza a perspectiva de que as práticas sociais constituídas no lugar constituem uma epistême que atualiza para os que não são do lugar, os conceitos para a Educação Ambiental, dentre eles a sustentabilidade. Para tanto, a estrutura axiológica dos mais diversos 
povos tem como forte fundamento a defesa do território, e consequentemente da sociobiodiversidade existente nele, destoando de conceitos que não valoram as necessidades e particularidades do lugar.

Ao apresentar trechos do documento Programa latino-americano e caribenho de educação ambiental no marco do desenvolvimento sustentável buscamos uma perspectiva que vise à desconstrução do modelo de se pensar a Educação Ambiental, apontado no primeiro documento: o Education for Sustainable Development.

Uma Educação Ambiental, que se constitui não apenas nos espaços formais para a educação, em especial as escolas e universidades, mas também nos mais diversos territórios e lugares, em que haja uma íntima relação do ser humano com a natureza.

Educação Ambiental constituída, a partir de uma postura pós-colonial que cria condições para a emergência de saberes que historicamente foram tornados ausentes, não se limitando a caminhos que apontem que o sustentável ocorre apenas na perspectiva de desenvolvimento produzida pelo mundo moderno-colonial. Postura, que propicia a emergência de concepções sustentabilidades, que reconheçam as potencialidades culturais e a sociobiodiversidade existentes no lugar.

Ao acontecer com o vivido, e que por conta da multiplicidade de histórias, saberes e culturas existentes no mundo, compreendemos a Educação Ambiental, não se delineando em um desenvolvimento sustentável, como uma face de um colonialismo, que descreve, não como ele é, mas como ele está sendo feito, ou como ele deveria ser, para todos os lugares, a partir de um discurso de progresso e desenvolvimento. Educação Ambiental, que, vise dar potência as sustentabilidades existentes com as comunidades tradicionais, não com a pretensão de se tornar absoluto, e sim, de possibilitar ressonâncias de construção de outras trajetórias sustentáveis, elaborados por seus protagonistas, em diferentes locais, com a natureza e com o lugar.

Com isto, pretendemos propiciar que a Educação Ambiental saia da armadilha paradigmática, Guimarães (2006), que fraciona e reduz. Uma educação na qual o seu saber, seja fundado a partir da diversidade cultural, ambiental, e vivida, tal como existente em uma reserva extrativista, com as quebradeiras de coco. Que valorize o conhecimento singular, subjetivo, emancipador e autônomo como: “[...] uma prática intersubjetiva que produz uma 
série de efeitos sobre a aplicação dos conhecimentos das ciências e sobre a integração de um conjunto de saberes não-científicos.” (LEFF, 2006, p.174).

Intentamos para a Educação Ambiental, que esta tenha como percurso para se desvencilhar da armadilha do paradigma moderno-cientificista, a Sociologia das Ausências (SANTOS, 2010), a compreendendo como uma investigação que visa demonstrar que o que não existe é, na verdade, produzido como não existente. A lógica do mundo moderno-colonial e da ciência constituída por essa matriz de ver o mundo nos induz a presumir a não existência de outros saberes e práticas cotidianas, que existem no real, no vivido, e, portanto de outras possibilidades de Educação Ambiental.

Isto pressupõe, neste estudo, uma construção epistêmica que permita expandir a compreensão de que existem lógicas sustentáveis para além de uma vertente imposta de desenvolvimento sustentável. Lógicas apoiadas na Sociologia das Emergências, (SANTOS, 2010) ao compreendermos que visibilizar a sustentabilidade produzida em comunidades tradicionais, é uma investigação das alternativas que cabem no horizonte das possibilidades concretas, como experiências sociais possíveis.

Pretendemos contribuir para se pensar uma alternativa de sustentabilidade, cujas possibilidades perpassem por processos de envolvimento com a natureza, sobretudo a partir da territorialização das culturas. O que não significa que haverá uma idealização da cultura dos extrativistas, em sua relação com a natureza, pois senão correríamos o risco de tornarmos homogêneas as práticas sustentáveis e não sustentáveis existentes na RESEX. Caso houvesse essa idealização, romperíamos com a proposição de diálogo de saberes e direcionaríamos o entendimento de que tais práticas se consolidariam como uma metanarrativa da sustentabilidade.

Para tanto, no sentido de não idealizarmos uma determinada cultura, a entendemo-la como Geertz (2008), como um universo de significações, no qual os homens e mulheres a constituem em uma tessitura realizada por eles mesmos. Assim, essas significações são constituídas em uma relação íntima do ser humano com a natureza e com seus pares, com suas subjetividades em seu ambiente, com o seu lugar, não sendo passíveis de tornarem-se homogêneas.

Portanto, a cultura em toda a sua diversidade e com suas singularidades passa a ser entendida como uma atividade produtora que propicia outras possibilidades de entendermos 
uma relação sustentável da humanidade para com a Terra. Cultura que se torna preponderante na produção de um processo educativo, que para a Educação Ambiental, tenha uma estrutura axiológica de saberes e valores constituídos na vivência dos mais diversos povos tradicionais, na medida em que: “A cultura é mais do que produto e ato. É modo de produzir. É hábito cultural, ético, intelectual, não só objeto produzido e preservado e ensinado às novas gerações" (ARROYO, 2012, p.104).

\section{Alternativa de sustentabilidade em uma reserva extrativista}

Na região norte do estado Tocantins, mais especificamente ao Norte da estrada TO496 e ao Sul do rio Tocantins, na divisa com o Estado do Pará, a Oeste, e com o Estado do Maranhão, a leste localiza-se a reserva extrativista do Extremo norte do Tocantins.

A rica cultura e os saberes constituídos pelas quebradeiras de coco, que vivem nesta reserva, refletem-se em uma defesa da sociobiodiversidade cujas atividades primeiras de relação da humanidade com a natureza, permitem maior envolvimento entre ambos, a partir de uma territorialização e de um lugaridade de determinada área, utilizada por populações tradicionais, cuja autossuficiência baseia-se no extrativismo.

Extrativismo alicerçado pelo coco babaçu (attalea speciosa). Do coco babaçu são originados diversos outros subprodutos, os quais destacamos alguns que possuem maior importância na vida dos extrativistas na RESEX. Da amêndoa é originado o azeite, em um processo de produção artesanal. Inicialmente há a torragem da amêndoa. Na sequência, esta, passa por um processo de moagem em um pilão e posterior cozimento para que, enfim, o azeite esteja pronto para consumo.

O óleo é outro subproduto derivado da amêndoa. Este é produzido a partir de um processo de extração em maquinários específicos. Este subproduto atualmente representa a principal fonte de renda para aqueles que vivem do coco babaçu na RESEX.

O óleo, assim como o azeite, substitui o óleo de soja, de milho, dentre outros, no preparo de diversos alimentos. O processo de extração para produção do óleo resulta em mais um subproduto, a torta derivada do bagaço da amêndoa. A torta serve para ração animal e é vendida inclusive para pecuaristas da região, sendo mais uma fonte de renda para os extrativistas. 
Da casca do coco produz-se o carvão. A queima do coco é realizada na caieira, um forno artesanal produzido pelos extrativistas. Este forno consiste na abertura de buracos feitos no solo, no qual as cascas são condicionadas em um barril metálico que se encaixa nesses buracos. Por fim, as cascas do coco babaçu, são abafadas com folhas da palmeira do babaçu e com a própria terra.

Outro subproduto é o mesocarpo, do qual se extrai uma farinha de amido para produção de mingau e bolo. As larvas presentes em alguns dos cocos, conhecidas como gongo, também são utilizadas na alimentação.

Há ainda o aproveitamento de partes da palmeira, como as folhas que servem tal e qual cobertura/telhado de casas e para a confecção de cestos e artesanatos; a estrutura da taipa que compõe as paredes das moradias feitas com os talos das folhas, bem como do caule que uma vez apodrecido, serve de adubo orgânico.

Compreendemos que as vivências das quebradeiras de coco, que buscam se relacionar com o máximo possível de elementos que a Terra, o lugar, a propiciam, nos concedem pensarmos uma Educação Ambiental que se realize em uma RESEX e na qual tenhamos uma alternativa de sustentabilidade ocorrendo de maneira dissonante ao modelo de desenvolvimento sustentável imposto e pensado como único.

\section{Caminhos para uma alternativa de sustentabilidade}

Para desenvolver a análise documental, além de contar com os documentos selecionados - a partir de uma pesquisa realizada com o objetivo de buscar documentos oficiais e norteadores para a Educação Ambiental, bem como de documentos produzidos com o intuito de serem "universais" -, foram delimitados termos-chave, conforme aponta Pimentel (2001). Desenvolvimento sustentável e Educação Ambiental foram os nossos termos-chave, a fim de aprofundarmos os conteúdos dos documentos com o objetivo do artigo.

Entendemos que a análise já realizada dos documentos citados terem constado em outro momento deste texto, tornou-se necessária como uma estratégia, para que as tramas deste escrito pudessem ganhar uma maior consistência epistêmica e metodológica na proposição do objeto e nos passos para a sua concepção.

A técnica da narrativa - que contribui para a estruturação da experiência humana, visto que narrar é relatar acontecimentos vividos - foi a utilizada, para compreendermos as 
possibilidades de sustentabilidades alternativas nas descrições de três quebradeiras de coco. Para compreendermos as narrativas das quebradeiras de coco, não lançamos mão de uma questão específica, mas, sim solicitamos que estas narrassem sua experiência com o lugar, Tais narrativas foram gravadas em arquivos digitais de áudio.

Assim, examinar as produções narrativas, a partir das histórias contadas, concede significado e valor à existência. Além disso, compreender outras racionalidades repletas de saberes locais não é apenas explicar uma etapa na história do pensamento humano; é, também, entender melhor outras possibilidades de alternativa de sustentabilidade.

Os trechos reproduzidos em seguida, são narrativas decorrentes de estudos realizados pelo Grupo de Estudos sobre Educação Ambiental e Sustentabilidade (GEAS), e que foram produzidas em comunidades distintas que compõem a reserva extrativista do Extremo Norte do Tocantins. Estudos que marcam a realização da produção de dados do processo de doutoramento $^{3}$, que se encontra em fase final, na busca da compreensão de aspectos das culturas e saberes sustentáveis em uma comunidade tradicional.

Selecionamos histórias que consideramos representativas para apresentar saberes e culturas das quebradeiras de coco que caracterizam uma alternativa de sustentabilidade. Logo, entendemos que as narrativas têm a capacidade de tornar sensíveis aos pesquisadores as experiências dos narradores a partir do contar das histórias vivenciadas tais como elas acontecem.

\section{Quebradeira 1}

A luta é pesada, mas nós vamos vencendo. Tem 40 anos que moro no Cacheado (comunidade da reserva extrativista localizada no município de Sampaio, no Tocantins). Nasci no Piauí em Teresina. Vim pra cá pequena. Meus pais vieram pra trabalhar. Era o que sabiam fazer: Quebrar coco e fazer roça. Bom, né? Eu acho muito. Tem gente que não sabe fazer nada. Nós vai aprendendo com eles. Hoje eu vendo só o coco. As cascas tamos usando para fazer carvão, pra cozinhar e pra vender. Vendia pra os vizinhos mesmo. Ainda bem que aprendi a fazer estas coisas aqui. Aprendi a quebrar coco com meu pai, que me ensinou. Já pensou se ele não tivesse me ensinado? Meu filho sabe quebrar coco. Ele ia pro mato mais eu. Ele quebra

\footnotetext{
${ }^{3}$ Em Ciências do Ambiente, de Fábio Pessoa Vieira, na Universidade Federal do Tocantins, sob orientação de Lucas Barbosa e Souza
} 
só pra chupar. Ele juntava coco, ele fazia uma caieira, trazia pra casa. Fazia uma roça.

\section{Quebradeira 2}

Nasci aqui no Carrasco Bonito (município do Tocantins). Trabalho com o coco aqui, apesar de não quebrar muito não. A mãe ensinou, mas eu não sou muito boa não. Morei um ano em Palmas, aí que perdi o jeito. Hoje eu ajudo aqui mais na extração do óleo. Ajudo muito o povo aqui [...] De vez em quando, o coco tá verde (úmido). Aí ele não tava passando na máquina. Ficava embuchando. Ele seco é melhor. Deixamos uma semana aí secando, senão ele rende muito pouco. Passamos na máquina em média de uns 150 kilos por semana. Isso só aqui da comunidade de Carrasco Bonito. Quando juntamos de todas as comunidades, dá uns 400 kilos. Tem umas quebradeiras que já deixam secando em casa. Aí já ajuda o trabalho aqui. Por exemplo, se elas deixarem secando na quinta-feira e trazerem na sextafeira não deu tempo de secar. Tem de ficar uma semana secando. Todo mundo já sabe que temos de secar o coco. Aprendemos isso há muito tempo, com nossas famílias. Quando ele tá meio verdoso, rende menos. Coco de inverno (na verdade é o verão, período chuvoso, na região) é assim mesmo. [...] As vezes nós pegamos coco que caiu há dois anos, e ele tá bonzinho para processar.

\section{Quebradeira 3}

Aqui eu planto muita mandioca, além de quebrar o coco. Tem mandioca aqui no quintal de casa, que eu tenho de colher até o final de mês de outubro. Até novembro no máximo tá no tempo de rancar. Se não rancar eu perco. Planto no quintal porque é a terra onde tenho e aqui é tudo plano. A nossa casa de farinhada hoje é nosso sonho. Porque a gente não tem carro pra levar pra fazer em outra casa de farinhada. Aí ficava uma despesa do caramba, que a gente não aguenta. A mandioca complementa demais a renda, além do coco. Aprendi a plantar com meu pai. O coco eu aprendi com a precisão, meu filho! Nem lembro quem me ensinou. Desde pequena, nem lembro. Acho que eu tinha uns 7 anos quando comecei a quebrar coco. Aprendi com as quebradeiras no meio do mato mesmo. Eu fui criada sem mãe, meu pai não deixava a gente quebrar coco. Daí aprendi com as quebradeiras pra pegar o dinheiro e comprar roupa pra mim, pra ficar mais arrumada. 


\section{Considerações Finais}

O presente texto intentou apresentar uma alternativa, de sustentabilidade local, ao conceito de desenvolvimento sustentável, elaborado pela ONU, destacando as ressonâncias de tal conceito, na Educação Ambiental, engendrado pelo mundo moderno-colonial.

Tais ressonâncias foram apontadas em dois documentos norteadores da Educação Ambiental na contemporaneidade. Um que expõe uma abordagem homogênea, em um viés colonizador e hegemônico, sobre o desenvolvimento sustentável, e outro elaborado e pensado para permitir outros percursos de sustentabilidade, para a Educação Ambiental.

Para tanto, apoiados em uma perspectiva pós-colonial, apresentamos algumas histórias de vida de quebradeiras de coco, da Reserva Extrativista do Extremo Norte do Tocantins como possibilidades de sustentabilidade, para a Educação ambiental. Por conseguinte, buscamos propiciar compreensões: de que a sociedade não é una e que, portanto, há uma diversidade de possibilidades de relações da humanidade com a natureza em uma realidade complexa que extrapola os ideais de um modelo de desenvolvimento sustentável; que há possibilidade da Educação Ambiental ter como alicerce os saberes elaborados em uma cultura constituída a partir de uma relação de intimidade com a natureza.

Saberes produzidos por comunidades tradicionais, exemplificadas com as quebradeiras de coco, concedendo assim à Educação Ambiental, um exercício ético, epistêmico e contrahegemônico, na produção do conhecimento.

\section{Referências}

ARROYO, M. Outros sujeitos, outras pedagogias. Rio de Janeiro, Petrópolis: Vozes, 2012.

BRASIL. Secretaria de Educação Fundamental. Parâmetros curriculares nacionais: meio ambiente. Brasília: MEC/SEF DF, 1998.

BRASIL. Ministério do Meio Ambiente: Programa Latino-americano e Caribenho de Educação Ambiental. Brasília: MMA, 2005. Disponível em < http://www.mma.gov.br/port/sdi/ea/placea/arqs/doctec5_placea.pdf $>$ Acesso em 10 de Março de 2016.

COMISSÃO MUNDIAL SOBRE MEIO AMBIENTE E DESENVOLVIMENTO. Nosso futuro Comum. Rio de Janeiro: Fundação Getúlio Vargas, 1991. 
GEERTZ, C. A interpretação das culturas. Rio de Janeiro: LTC, 2008.

GUIMARÃES, M. A formação de educadores ambientais. Campinas: Papirus, 2004.

GUIMARÃES, M. Armadilha paradigmática na Educação Ambiental. In: LOUREIRO, C. F. B; LEROY, J. P. (Orgs.). Pensamento complexo, dialética e Educação Ambiental. São Paulo: Cortez, 2006.

LAYRARGUES, P. P. Educação para a gestão ambiental: a cidadania no enfrentamento político dos conflitos socioambientais. In: LOUREIRO, C. F. B.; LAYRARGUES, P. P.; CASTRO, R. S. de (Orgs.). Sociedade e meio ambiente: a educação ambiental em debate. 4.ed. São Paulo: Cortez, 2006.

LEFF, E. Epistemologia Ambiental. 4. ed. São Paulo: Cortez, 2006.

LOUREIRO, C. F. B. Trajetórias e fundamentos da educação ambiental. 2. ed. São Paulo: Cortez, 2006.

MARANDOLA Jr, E. Lugar Enquanto Circunstancialidade In: MARANDOLA Jr, E.; HOLZER, W.; OLIVEIRA, L. de (Orgs). Qual o espaço do lugar?: geografia, epistemologia, fenomenologia. São Paulo: Perspectiva, p.227-247, 2014.

MCKEOWN, R. Education for sustainable development Toolkit. University of Tennessee, 2002. Disponível em: 〈http://www.esdtoolkit.org/esd_toolkit_v2.pdf >

MIGNOLO, W. A colonialidade de cabo a rabo: o hemisfério ocidental no horizonte conceitual da modernidade. In: LANDER E. (Org.). A colonialidade do saber: eurocentrismo e ciências sociais - Perspectivas latino-americanas. Buenos Aires: Clacso, 2005.

PIMENTEL, A. O Método da Análise Documental: seu uso numa pesquisa historiográfica. Cadernos de Pesquisa. São Paulo, n.114, p.179-195, 2001.

PORTO-GONÇALVES, C. W. A Globalização da natureza e a natureza da globalização. $5^{\circ}$ ed. Rio de Janeiro: Civilização Brasileira, 2013.

QUIJANO, A. Colonialidade do poder, eurocentrismo e América Latina. In: LANDER, E. (Org.). A colonialidade do saber: eurocentrismo e ciências sociais - Perspectivas latinoamericanas. Buenos Aires: Clacso, 2005.

REIGOTA, M. Meio Ambiente e Representação Social. São Paulo: Cortez, 1995.

RELPH, E. As Bases Fenomenológicas da Geografia. Geografia. Rio Claro, v.4, n.7, p.1-25, 1979. 
SILVA, L. A. G. Conceição. Biomas presentes no Estado do Tocantins. Brasília: Consultoria Legislativa, ago. 2007. Disponível em: http://www.terrabrasilis.org.br/ecotecadigital/images/abook/pdf/1sem2015/Passivo/biomastoc antins.pdf $>$

SÁ-SILVA, J. R.; ALMEIDA, C. D.; GUINDANI, J. F. Pesquisa documental: pistas teóricas e metodológicas. Revista Brasileira de História e Ciências Sociais. São Leopoldo, v.1, n.1, p. 1-15, jul. 2009.

SANTOS, B. S. A Gramática do Tempo: para uma nova cultura política. 3. ed. São Paulo: Cortez, 2010. 